\author{
MARÍA DEL CARMEN PAREDES \\ Universidad de Salamanca \\ paredes@usal.es
}

\title{
Bibliografía sobre Hegel en español del año 2016
}

\section{Bibliography on Hegel in Spanish of the year 2016}

RESUMEN: Recopilación por orden alfabético de los estudios en español que se ocupan directamente de Hegel y que fueron publicados en 2016 y registrados en las principales bases de datos. Se incluyen tanto las monografías, como las contribuciones en revistas especializadas en obras colectivas.

PALABRAS CLAVE: HEGEL-BIBLIOGRAFÍA
ABSTRACT: Compilation in alphabetical order of studies on Hegel written in Spanish and published along 2016, as registered in the main basedata. This bibliography includes monographies as well as articles in specialized reviews and collective works. KEY WORDS: HEGEL-BIBLIOGRAPHY

Alonso Olea, Manuel. Variaciones sobre Hegel, Cizur Menor (Navarra): Aranzadi, 2016.

Ángeles Acosta Villavicencio de los, Sofía. "Hegel y la muerte del arte". Xipe Totek 25, 2 (2016): 118-144.

Antón Pacheco, José Antonio/ Rodríguez Tous, Juan Antonio. Los días de Hegel en Missouri, Sevilla: Univ. de Sevilla, 2016.

AragüÉs Aliaga, Rafael. “Crítica y refutación lógica del spinozismo”. Studia Hegeliana 2 (2016): 9-22.

Arias Krause, Juan Ignacio/Landaeta Mardones, Patricio. "El desequilibrio de lo político en Hegel”. Tópicos: Revista de Filosofía (México) 51 (2016): 139-158. 
Bataille, Georges. Escritos sobre Hegel, Madrid: Arena Libros, 2016.

Benavides, Cristian Eduardo. "La crítica kierkegaardiana a la concepción hegeliana de libertad según la interpretación de Cornelio Fabro”. Arete: Revista de Filosofía 28 (1), (2016): 89-104.

Binetti, María José, Kierkegaard y el idealismo: lineamientos de su proximidad histórica. México: Facultad de Filosofía y Letras. Universidad Nacional Autónoma de México, 2016.

Bobbio, Norberto. "Sobre la noción de constitución en Hegel”. Anales de la Cátedra Francisco Suárez 50 (2016): 71-82.

Calderón González, Jacinto Habded. "El alma bella: angustia e inactividad”. Cuadernos de Filosofía Latinoamericana 37, 115 (2016): 217-234.

Cantillo, Clementina, Para una crítica de la razón vital: entre Hegel y Ortega. Madrid: Biblioteca Nueva, 2016.

Cantillo, Clementina. «La dinámica histórica entre energía mediterránea y pensamiento del Norte: La confrontación de Ortega con Hegel». La brújula hacia el sur: Estudios sobre filosofía meridional, Badillo O’Farrell, Pablo/Sevilla Fernández, José M (eds.), 87-100. Madrid: Biblioteca Nueva, 2016.

Cardani, Michele. F.H. Bradley: ¿un spinozista hegeliano?". Studia Hegeliana 2 (2016): 53-68.

Casanova, Mauricio. La sociología sin método. La raíz hegeliana del pensamiento de Luhmann. Santiago de Chile: Universidad de Chile. Facultad de Ciencias Sociales, 2016.

Castiglioni, German Daniel. "Marx sin reservas. Seis tesis para interpretar El capital a partir de la Lógica de Hegel”. Ideas y Valores: Revista Colombiana de Filosofía. 65, 161 (2016): 287-313.

Comba, Antonella. “¿Filosofía hegeliana en el Derecho Penal del Enemigo? Distancias entre Gunther Jakobs y la Filosofía del Derecho de Hegel”. Anuario de Filosofía del Derecho 32 (2016): 213-233. 
Cordero Redondo, Joan J. “¿De qué trata la Filosofía del Derecho de G. W. F. Hegel?”. Revista de Filosofía de la Universidad de Costa Rica 55, 143 (2016): 25-36.

Cuartango, Román G. El poder del espíritu. Hegel y el ethos político. Madrid: Abada, 2016.

DRI, RUBÉN. HEGEL. La doctrina de la esencia y las contradicciones en el camino de la creación del sujeto y del Estado, Buenos Aires: Editorial Biblos, 2016.

Eduardo Benavides, Cristian. «La crítica kierkegaardiana a la concepción hegeliana de libertad según la interpretación de Cornelio Fabro». Areté: Revista de Filosofía 28, 1 (2016): 89-104.

Espinoza Lolas, Ricardo. Hegel y las nuevas lógicas del mundo y del Estado. Madrid: Akal, 2016.

Espinoza Lolas, Ricardo/Landaeta Mardones, Patricio/Arias, Juan IgNACio. "Hegel y las redes lógicas como diseñadoras de la realidad". Anales del Seminario de Historia de la Filosofía 33, 2 (2016): 583-603.

EzQuerra, Jesús. "Hegel, la herida". Contrastes: Revista Interdisciplinar de Filosofía 21, 1 (2016): 79-93.

Guzmán, Luis. "De dualismo y domesticaciones: Davidson, McDowell, Hegel". Ideas y Valores: Revista Colombiana de Filosofía 65, 160 (2016): 75-93.

Heidegger, M. La fenomenología del espíritu de Hegel (curso del semestre de invierno Friburgo, 1930-31) I.Görland (ed.). Madrid: Alianza Editorial, 2016.

Herrero, Montserrat. "Religión y política: la respuesta de la filosofía de Hegel entre tensión y reconciliación". Pensamiento. Revista de Investigación e Información Filosófica 72, 271 (2016): 279-294.

Honneth, Axel/Hernàndez, i Dobon, Francesc Jesús/Herzog, Benno. Patologías de la libertad. Buenos Aires: Editorial las Cuarenta, 2016. 
Lefebvre, Henri/Arminño, Mauro. Hegel, Marx, Nietzsche (o el reino de las sombras). Madrid: Siglo XXI, 2016.

Moder, Gregor. "La recepción francesa de Hegel en las postrimerías del siglo XX: Spinoza y la tradición neoplatónica”. Studia Hegeliana 2 (2016): 127-140.

Nieves Loja, Gerardo Miguel. "El perdón como renuncia a la venganza. Algunas reflexiones filosóficas". Erasmo 3 (2016): 100-111.

Ortega Muñoz, Juan Fernando. «El sentido de la historia: S. Agustín, Hegel, Marx. Un estudio comparativo». Identidad, memoria e historia. Actas de los XII encuentros internacionales de filosofía en el Camino de Santiago. Univ. Santiago de Compostela (2016): 203-215.

Parcero Oubiña, Óscar. "La emancipación del prólogo en la 'Fenomenología del espíritu”. Anales del Seminario de Historia de la Filosofía 33, 2 (2016): 561-582.

Profili, Lelia Edith. "Operaciones fundamentales de la lógica genética". Anuario Filosófico 49, 3 (2016): 585-607.

Sánchez Cuervo, Antolín. “Ortega y Hegel. La interpretación de la historia y sus trampas”. Daimon. Revista de Filosofía 67 (2016): 57-72.

Solé Plans, Sergi. "Apuestas de razón. Residencia en Kant y Hegel”. Revista de la Asociación Española de Neuropsiquiatría 36, 130 (2016): 499-513.

Ripalda, José María. La nación dividida: las raíces de un pensador burgués. G.W.F. Hegel. (reed.) Madrid: Abada, 2016.

Solarte Rodríguez, Mario Roberto. Violencia e institución. Aportes para una ética de la responsabilidad social. Bogotá: Editorial Pontificia Universidad Javeriana, 2016.

Trujillo, Iván. "Una diferencia sin como tal: Derrida y su diferencia con Heidegger" Pensamiento. Revista de Investigación e Información Filosófica 72, 270 (2016): 5-25. 
Valencia, Felipe. "Furor, industria y límites de la palabra poética en Hegel" Criticón (2016): 97-110.

VAnegas Zubiría, Carlos Mario. "La apariencia (Schein) en las Lecciones sobre la Estética de Hegel”. Estudios de Filosofía 53 (2016): 35-55.

Vega de ORdUÑa, José LUIS DE LA. Iusnaturalismo y eticidad: una aproximación a la sociedad civil en Hegel. Madrid: Apeiron, 2016.

Vitor IbARRA, B. "La condena sin venganza privada tras la justicia punitiva”. Ideas y Valores: Revista Colombiana de Filosofía 65, 162 (2016): 291-314

Zizek, Slavoj/Bello, Ana. El resto indivisible, Buenos Aires: Ediciones Godot 2016. 
